Article

\title{
Reformulated First Zagreb Index of Some Graph Operations
}

Nilanjan De $^{1, *}$, Sk. Md. Abu Nayeem ${ }^{2}$ and Anita Pal ${ }^{3}$

${ }^{1}$ Department of Basic Sciences and Humanities (Mathematics), Calcutta Institute of Engineering and Management, Kolkata 700040, India

${ }^{2}$ Department of Mathematics, Aliah University, DN-20, Sector-V, Salt Lake, Kolkata 700091, India; E-Mail:nayeem.math@aliah.ac.in

${ }^{3}$ Department of Mathematics, National Institute of Technology, Durgapur 713209, India;

E-Mail:anita.buie@gmail.com

* Author to whom correspondence should be addressed; E-Mail: de.nilanjan@ rediffmail.com; Tel.:+91-983-127-8235.

Academic Editor: Lokenath Debnath

Received: 18 July 2015 / Accepted: 13 October 2015 / Published: 16 October 2015

\begin{abstract}
The reformulated Zagreb indices of a graph are obtained from the classical Zagreb indices by replacing vertex degrees with edge degrees, where the degree of an edge is taken as the sum of degrees of the end vertices of the edge minus 2. In this paper, we study the behavior of the reformulated first Zagreb index and apply our results to different chemically interesting molecular graphs and nano-structures.
\end{abstract}

Keywords: topological index; vertex degree; Zagreb indices; reformulated Zagreb indices; graph operations

MSC classifications: Primary: 05C35; Secondary: 05C07, 05C40

\section{Introduction}

Suppose $\sum$ denotes the class of all graphs, then a function $T: \sum \rightarrow \mathbf{R}^{+}$is known as a topological index if for every graph $H$ isomorphic to $G, T(G)=T(H)$. Different topological indices are found to be useful in isomer discrimination, structure-property relationship, structure-activity relationship, pharmaceutical drug design, etc. in chemistry, biochemistry and nanotechnology. Suppose $G$ is a simple connected graph and $V(G)$ and $E(G)$ respectively denote the vertex set and edge set of $G$. Let, for any 
vertex $v \in V(G), d_{G}(v)$ denotes its degree, that is the number of neighbors of $v$. Let $n$ vertices of $G$ be denoted by $v_{1}, v_{2}, \ldots, v_{n}$. If the edges of $G$ are $\left(v_{1}, v_{2}\right),\left(v_{2}, v_{3}\right) \ldots .\left(v_{n-1}, v_{n}\right),\left(v_{n-1}, v_{n}\right)$ then the graph is called a path graph and is denoted by $P_{n}$. The wheel graph, denoted by $W_{n}$, is obtained by adding a new vertex to the cycle $C_{n}$ and connects this new vertex to each vertex of $C_{n}$. Similarly, a fan graph $F_{n}$, is obtained by adding a new vertex to the path graph $P_{n}$ and connects this new vertex to each vertex of $P_{n}$. The first and second Zagreb indices of a graph, denoted by $M_{1}(G)$ and $M_{2}(G)$ are among the oldest, most popular and most extensively studied vertex-degree-based topological indices. These indices were introduced Gutman and Trinajstić in a paper in 1972 [1] to study the structure-dependency of the total $\pi$-electron energy $(\varepsilon)$ and are respectively defined as

$$
M_{1}(G)=\sum_{v \in V(G)} d_{G}(v)^{2}=\sum_{u v \in E(G)}\left[d_{G}(u)+d_{G}(v)\right]
$$

and

$$
M_{2}(G)=\sum_{u v \in E(G)} d_{G}(u) d_{G}(v)
$$

These indices are extensively studied in (chemical) graph theory. Interested readers are referred to [2,3] for some recent reviews on the topic. Milićević et al. [4] reformulated the Zagreb indices in terms of edge degrees instead of vertex degrees, where the degree of an edge $e=u v$ is defined as $d(e)=d(u)+d(v)-2$. Thus, the reformulated first and second Zagreb indices of a graph $G$ are defined as

$$
E M_{1}(G)=\sum_{e \in E(G)} d(e)^{2} \text { and } E M_{2}(G)=\sum_{e \sim f} d(e) d(f)
$$

where $e \sim f$ means that the edges $e$ and $f$ share a common vertex in $G$, i.e., they are adjacent. Different mathematical properties of reformulated Zagreb indices have been studied in [5]. In [6], Ilić et al., establish further mathematical properties of the reformulated Zagreb indices. In [7], bounds for the reformulated first Zagreb index of graphs with connectivity at most $k$ are obtained. De [8] found some upper and lower bounds of these indices in terms of some other graph invariants and also derived reformulatrd Zagreb indices of a class of dendrimers [9]. Ji et al. [10,11] computed these indices for acyclic, unicyclic, bicyclic and tricyclic graphs.

Graph operations play a very important role in mathematical chemistry, since some chemically interesting graphs can be obtained from some simpler graphs by different graph operations. In [12], Khalifeh et al., derived some exact expressions for computing first and second Zagreb indices of some graph operations. Ashrafi et al. [13] derived explicit expressions for Zagreb coindices of different graph operations. Das et al. [14] derived some upper bounds for multiplicative Zagreb indices of different graph operations. Azari and Iranmanesh [15], presented explicit formulae for computing the eccentric-distance sum of different graph operations. In [16] and [17], the present authors obtained some bounds and exact formulae for the connective eccentric index and for F-index of different graph operations. There are several other papers concerning topological indices of different graph operations. For more results on topological indices of different graph operations, interested readers are referred to the papers [18-22].

In this paper we present some exact expressions for the reformulated first Zagreb index of different graph operations such as join, Cartesian product, composition, corona product, splice and link of 
graphs. Also we apply our results by specializing components of these graph operations to compute the reformulated first Zagreb index for some important classes of molecular graphs and nano-structures.

\section{Main Results}

In this section, we study the reformulated first Zagreb index under join, Cartesian product, composition, corona product, link and splice of graphs. All these operations are binary, and the join and Cartesian product of graphs are commutative operations, whereas the composition and corona product operations are noncommutative. All the graphs considered here are connected, finite and simple. Let $G_{1}$ and $G_{2}$ be two simple connected graphs, so that their vertex sets and edge sets are represented as $V\left(G_{i}\right)$ and $E\left(G_{i}\right)$ respectively, for $i \in\{1,2\}$.

\subsection{The Join of Graphs}

The join $G_{1}+G_{2}$ is the union $G_{1} \cup G_{2}$ together with all the edges joining each vertex of $V\left(G_{1}\right)$ to each vertex of $V\left(G_{2}\right)$. The degree of a vertex $v$ of $G_{1}+G_{2}$ is given by

$$
d_{G_{1}+G_{2}}(v)=\left\{\begin{array}{l}
d_{G_{1}}(v)+\left|V\left(G_{2}\right)\right|, v \in V\left(G_{1}\right) \\
d_{G_{2}}(v)+\left|V\left(G_{1}\right)\right|, v \in V\left(G_{2}\right)
\end{array}\right.
$$

In the following theorem we compute the reformulated first Zagreb index of the join of two graphs.

Theorem 1. The reformulated first Zagreb index of $G_{1}+G_{2}$ is given by

$$
\begin{aligned}
E M_{1}\left(G_{1}+G_{2}\right)= & E M_{1}\left(G_{1}\right)+E M_{1}\left(G_{2}\right)+5\left|V\left(G_{1}\right)\right| M_{1}\left(G_{2}\right)+5\left|V\left(G_{2}\right)\right| M_{1}\left(G_{1}\right) \\
& +\left|V\left(G_{1}\right)\right|\left|V\left(G_{2}\right)\right|\left(\left|V\left(G_{1}\right)\right|+\left|V\left(G_{2}\right)\right|-2\right)^{2}+8\left|E\left(G_{1}\right)\right|\left|E\left(G_{2}\right)\right| \\
& +4\left(\left|V\left(G_{1}\right)\right|+\left|V\left(G_{2}\right)\right|-2\right)\left(\left|V\left(G_{1}\right)\right|\left|E\left(G_{2}\right)\right|+\left|V\left(G_{2}\right)\right|\left|E\left(G_{1}\right)\right|\right) \\
& +4\left|V\left(G_{1}\right)\right|^{2}\left|E\left(G_{2}\right)\right|+4\left|V\left(G_{2}\right)\right|^{2}\left|E\left(G_{1}\right)\right|-8\left|V\left(G_{1}\right)\right|\left|E\left(G_{2}\right)\right| \\
& -8\left|V\left(G_{2}\right)\right|\left|E\left(G_{1}\right)\right| .
\end{aligned}
$$

Proof of Theorem 1. We have

$$
\begin{aligned}
E M_{1}\left(G_{1}+G_{2}\right)= & \sum_{u v \in E\left(G_{1}+G_{2}\right)}\left(d_{G_{1}+G_{2}}(u)+d_{G_{1}+G_{2}}(v)-2\right)^{2} \\
= & \sum_{u v \in E\left(G_{1}\right)}\left(d_{G_{1}+G_{2}}(u)+d_{G_{1}+G_{2}}(v)-2\right)^{2}+\sum_{u v \in E\left(G_{2}\right)}\left(d_{G_{1}+G_{2}}(u)+d_{G_{1}+G_{2}}(v)-2\right)^{2} \\
& +\sum_{\substack{u v \in\left\{u v: u \in V\left(G_{1}\right), v \in V\left(G_{2}\right)\right\} \\
=}}\left(d_{G_{1}+G_{2}}(u)+d_{G_{1}+G_{2}}(v)-2\right)^{2} \\
& J_{1}+J_{2}+J_{3}
\end{aligned}
$$


where $J_{1}, J_{2}$ and $J_{3}$ denote the sums of the above terms in order. Next we calculate $J_{1}, J_{2}$ and $J_{3}$ separately.

$$
\begin{aligned}
J_{1}= & \sum_{u v \in E\left(G_{1}\right)}\left(d_{G_{1}+G_{2}}(u)+d_{G_{1}+G_{2}}(v)-2\right)^{2} \\
= & \sum_{u v \in E\left(G_{1}\right)}\left(d_{G_{1}}(u)+d_{G_{1}}(v)+2\left|V\left(G_{2}\right)\right|-2\right)^{2} \\
= & \sum_{u v \in E\left(G_{1}\right)}\left(d_{G_{1}}(u)+d_{G_{1}}(v)-2\right)^{2}+4\left|V\left(G_{2}\right)\right| \sum_{u v \in E\left(G_{1}\right)}\left(d_{G_{1}}(u)+d_{G_{1}}(v)-2\right) \\
& +4 \sum_{u v \in E\left(G_{1}\right)}\left|V\left(G_{2}\right)\right|^{2} \\
= & E M_{1}\left(G_{1}\right)+4\left|V\left(G_{2}\right)\right|^{2}\left|E\left(G_{1}\right)\right|+4\left|V\left(G_{2}\right)\right|\left(M_{1}\left(G_{1}\right)-2 \mid E\left(G_{1}\right)\right) \mid .
\end{aligned}
$$

Similarly,

$$
\begin{aligned}
J_{2}= & \sum_{u v \in E\left(G_{2}\right)}\left(d_{G_{1}+G_{2}}(u)+d_{G_{1}+G_{2}}(v)-2\right)^{2} \\
= & \sum_{u v \in E\left(G_{2}\right)}\left(d_{G_{2}}(u)+d_{G_{2}}(v)+2\left|V\left(G_{1}\right)\right|-2\right)^{2} \\
= & \sum_{u v \in E\left(G_{2}\right)}\left(d_{G_{2}}(u)+d_{G_{2}}(v)-2\right)^{2}+4\left|V\left(G_{1}\right)\right| \sum_{u v \in E\left(G_{2}\right)}\left(d_{G_{2}}(u)+d_{G_{2}}(v)-2\right) \\
& +4 \sum_{u v \in E\left(G_{2}\right)}\left|V\left(G_{1}\right)\right|^{2} \\
= & E M_{1}\left(G_{2}\right)+4\left|V\left(G_{1}\right)\right|^{2}\left|E\left(G_{2}\right)\right|+4\left|V\left(G_{1}\right)\right|\left(M_{1}\left(G_{2}\right)-2\left|E\left(G_{2}\right)\right|\right) .
\end{aligned}
$$

Finally,

$$
\begin{aligned}
J_{3}= & \sum_{u v \in\left\{u v: u \in V\left(G_{1}\right), v \in V\left(G_{2}\right)\right\}}\left(d_{G_{1}+G_{2}}(u)+d_{G_{1}+G_{2}}(v)-2\right)^{2} \\
= & \sum_{u \in V\left(G_{1}\right), v \in V\left(G_{2}\right)}\left(d_{G_{1}}(u)+\left|V\left(G_{2}\right)\right|+d_{G_{2}}(v)+\left|V\left(G_{1}\right)\right|-2\right)^{2} \\
= & \sum_{u \in V\left(G_{1}\right), v \in V\left(G_{2}\right)}\left\{d_{G_{1}}(u)^{2}+d_{G_{2}}(v)^{2}+2 d_{G_{1}}(u) d_{G_{2}}(v)+\left(\left|V\left(G_{1}\right)\right|+\left|V\left(G_{2}\right)\right|-2\right)^{2}\right. \\
& \left.+2\left(d_{G_{1}}(u)+d_{G_{2}}(v)\right)\left(\left|V\left(G_{1}\right)\right|+\left|V\left(G_{2}\right)\right|-2\right)\right\} \\
= & \left|V\left(G_{2}\right)\right| M_{1}\left(G_{1}\right)+\left|V\left(G_{1}\right)\right| M_{1}\left(G_{2}\right)+8\left|E\left(G_{1}\right)\right|\left|E\left(G_{2}\right)\right|+\left|V\left(G_{1}\right)\right|\left|V\left(G_{2}\right)\right|\left(\left|V\left(G_{1}\right)\right|\right. \\
& \left.+\left|V\left(G_{2}\right)\right|-2\right)^{2}+4\left(\left|V\left(G_{1}\right)\right|+\left|V\left(G_{2}\right)\right|-2\right)\left(\left|V\left(G_{1}\right)\right|\left|E\left(G_{2}\right)\right|+\left|V\left(G_{2}\right)\right|\left|E\left(G_{1}\right)\right|\right) .
\end{aligned}
$$

Adding $J_{1}, J_{2}$ and $J_{3}$, we get the desired result.

Example 1. The complete bipartite graph $K_{p, q}$ is defined as join of $\bar{K}_{p}$ and $\bar{K}_{q}$, so that, from Theorem 1, its reformulated first Zagreb index is given by $E M_{1}\left(K_{p, q}\right)=p q(p+q-2)^{2}$.

The suspension of a graph $G$ is defined as $G+K_{1}$. Thus the reformulated first Zagreb index of a graph is calculated as follows. 
Corollary 2. The suspension of a graph $G$ is given by

$$
E M_{1}\left(G+K_{1}\right)=E M_{1}(G)+5 M_{1}(G)+n^{3}-2 n^{2}+n-8 m+4 n m .
$$

Example 2. The fan graph $F_{n}$ on $(n+1)$ vertices is the suspension of $P_{n}$. So, using Corollary 2, its reformulated first Zagreb index is calculated as

$$
E M_{1}\left(P_{n}+K_{1}\right)=n^{3}+2 n^{2}+13 n-32 .
$$

Example 3. The wheel graph $W_{n}$ on $(n+1)$ vertices is the suspension of $C_{n}$. So, its reformulated first Zagreb index is given by

$$
E M_{1}\left(C_{n}+K_{1}\right)=n^{3}+2 n^{2}+17 n \text {. }
$$

Example 4. The Dutch windmill graph or flower graph is the suspension of $m$ copies of $K_{2}$, denoted by $m K_{2}$. So its reformulated first Zagreb index is calculated as

$$
E M_{1}\left(K_{1}+m K_{2}\right)=8 m^{3}+4 m .
$$

\subsection{The Cartesian Product of Graphs}

Let $G_{1}$ and $G_{2}$ be two connected graphs. The Cartesian product of $G_{1}$ and $G_{2}$, denoted by $G_{1} \times G_{2}$, is the graph with vertex set $V\left(G_{1}\right) \times V\left(G_{2}\right)$. Any two vertices $\left(u_{p}, v_{r}\right)$ and $\left(u_{q}, v_{s}\right)$ are adjacent if and only if $\left[u_{p}=u_{q} \in V\left(G_{1}\right)\right.$ and $\left.v_{r} v_{s} \in E\left(G_{2}\right)\right]$ or $\left[v_{r}=v_{s} \in V\left(G_{2}\right)\right.$ and $\left.u_{p} u_{q} \in E\left(G_{1}\right)\right]$ and $r, s=1,2, \ldots,\left|V\left(G_{2}\right)\right|$.

In the following theorem we obtain the reformulated first Zagreb index of the Cartesian product of two graphs.

Theorem 3. The reformulated first Zagreb index of $G_{1} \times G_{2}$ is given by

$$
\begin{aligned}
E M_{1}\left(G_{1} \times G_{2}\right)= & \left|V\left(G_{1}\right)\right| E M_{1}\left(G_{2}\right)+\left|V\left(G_{2}\right)\right| E M_{1}\left(G_{1}\right)+12\left|E\left(G_{1}\right)\right| M_{1}\left(G_{2}\right) \\
& +12\left|E\left(G_{2}\right)\right| M_{1}\left(G_{1}\right)-32\left|E\left(G_{1}\right)\right|\left|E\left(G_{2}\right)\right| .
\end{aligned}
$$

Proof of Theorem 3. We have,

$$
\begin{aligned}
E M_{1}\left(G_{1} \times G_{2}\right)= & \sum_{(a, x)(b, y) \in E\left(G_{1} \times G_{2}\right)}\left(d_{G_{1} \times G_{2}}(a, x)+d_{G_{1} \times G_{2}}(b, y)-2\right)^{2} \\
= & \sum_{(a, x)(a, y), x y \in E\left(G_{2}\right)}\left(d_{G_{1} \times G_{2}}(a, x)+d_{G_{1} \times G_{2}}(a, y)-2\right)^{2} \\
& +\sum_{(a, x)(b, x), a b \in E\left(G_{1}\right)}\left(d_{G_{1} \times G_{2}}(a, x)+d_{G_{1} \times G_{2}}(b, x)-2\right)^{2} \\
= & A_{1}+A_{2}
\end{aligned}
$$


where $A_{1}$ and $A_{2}$ denote the sums of the above terms in order. Next we calculate $A_{1}$ and $A_{2}$ separately one by one. Now,

$$
\begin{aligned}
A_{1}= & \sum_{(a, x)(a, y), x y \in E\left(G_{2}\right)}\left(d_{G_{1} \times G_{2}}(a, x)+d_{G_{1} \times G_{2}}(a, y)-2\right)^{2} \\
= & \sum_{a \in V\left(G_{1}\right)} \sum_{x y \in E\left(G_{2}\right)}\left(2 d_{G_{1}}(a)+d_{G_{2}}(x)+d_{G_{2}}(y)-2\right)^{2} \\
= & 4 \sum_{x y \in E\left(G_{2}\right)} \sum_{a \in V\left(G_{1}\right)} d_{G_{1}}(a)^{2}+\sum_{a \in V\left(G_{1}\right)} \sum_{x y \in E\left(G_{2}\right)}\left(d_{G_{2}}(x)+d_{G_{2}}(y)-2\right)^{2} \\
& +4 \sum_{a \in V\left(G_{1}\right)} d_{G_{1}}(a) \sum_{x y \in E\left(G_{2}\right)}\left(d_{G_{2}}(x)+d_{G_{2}}(y)-2\right) \\
= & \left|V\left(G_{1}\right)\right| E M_{1}\left(G_{2}\right)+8\left|E\left(G_{1}\right)\right| M_{1}\left(G_{2}\right)+4\left|E\left(G_{2}\right)\right| M_{1}\left(G_{1}\right)-16\left|E\left(G_{1}\right)\right|\left|E\left(G_{2}\right)\right| .
\end{aligned}
$$

Similarly,

$$
\begin{aligned}
A_{2}= & \sum_{(a, x)(b, x), a b \in E\left(G_{1}\right)}\left(d_{G_{1} \times G_{2}}(a, x)+d_{G_{1} \times G_{2}}(b, x)-2\right)^{2} \\
= & \sum_{x \in V\left(G_{2}\right)} \sum_{a b \in E\left(G_{1}\right)}\left(2 d_{G_{2}}(x)+d_{G_{1}}(a)+d_{G_{1}}(b)-2\right)^{2} \\
= & 4 \sum_{a b \in E\left(G_{1}\right)} \sum_{x \in V\left(G_{2}\right)} d_{G_{2}}(x)^{2}+\sum_{x \in V\left(G_{2}\right)} \sum_{a b \in E\left(G_{1}\right)}\left(d_{G_{1}}(a)+d_{G_{1}}(b)-2\right)^{2} \\
& +4 \sum_{x \in V\left(G_{2}\right)} d_{G_{2}}(x) \sum_{a b \in E\left(G_{1}\right)}\left(d_{G_{1}}(a)+d_{G_{1}}(b)-2\right) \\
= & \left|V\left(G_{2}\right)\right| E M_{1}\left(G_{1}\right)+4\left|E\left(G_{1}\right)\right| M_{1}\left(G_{2}\right)+8\left|E\left(G_{2}\right)\right| M_{1}\left(G_{1}\right)-16\left|E\left(G_{1}\right)\right|\left|E\left(G_{2}\right)\right| .
\end{aligned}
$$

By adding $A_{1}$ and $A_{2}$, the desired result follows after simple calculation.

Let $P_{n}(n \geq 1)$ and $C_{n}(n \geq 3)$ be path and cycle of order $n$ respectively, then we have $E M_{1}\left(P_{n}\right)=4 n-10, E M_{1}\left(K_{n}\right)=2 n(n-1)(n-2)^{2}$ and $E M_{1}\left(C_{n}\right)=4 n$.

Example 5. The Ladder graph $L_{n}$, made by $n$ square and $2 n+2$ vertices is the Cartesian product of $P_{2}$ and $P_{n+1}$, so the reformulated first Zagreb index of $L_{n}$ is given by $E M_{1}\left(L_{n}\right)=48 n-36$.

Example 6. For a $C_{4}$-nanotorus $T C_{4}(m, n)=C_{n} \times C_{m}$, the reformulated first Zagreb index is given by $E M_{1}\left(T C_{4}(m, n)\right)=72 n m$.

Example 7. For a $C_{4}$-nanotube $T U C_{4}(m, n)=P_{n} \times C_{m}$, the reformulated first Zagreb index is given by $E M_{1}\left(T U C_{4}(m, n)\right)=72 n m-98 m$.

Example 8. The reformulated first Zagreb index of the grids $\left(P_{n} \times P_{m}\right)$ is given by

$$
E M_{1}\left(P_{n} \times P_{m}\right)=72 m n-98 m-98 n+112 .
$$

Example 9. The n-prism is defined as the Cartesian product of $K_{2}$ and $C_{n}$. The reformulated first Zagreb index of the n-prism is given by $E M_{1}\left(K_{2} \times C_{n}\right)=48 n$. 
Example 10. The rook's graph is defined as the Cartesian product of two complete graphs, say $K_{n}$ and $K_{m}$. So, the reformulated first Zagreb index of the rook's graph is given by

$$
\begin{aligned}
E M_{1}\left(K_{n} \times K_{m}\right)= & 2 m n\left[(m-1)(m-2)^{2}+(n-1)(n-2)^{2}+3(n-1)(m-1)^{2}\right. \\
& \left.+3(m-1)(n-1)^{2}-4(n-1)(m-1)\right] .
\end{aligned}
$$

\subsection{Composition}

This operation is also termed the lexicographic product. The composition of two graphs $G_{1}$ and $G_{2}$ is denoted by $G_{1}\left[G_{2}\right]$ and any two vertices $\left(u_{1}, u_{2}\right)$ and $\left(v_{1}, v_{2}\right)$ are adjacent if and only if $u_{1} v_{1} \in E\left(G_{1}\right)$ or $\left[u_{1}=v_{1}\right.$ and $\left.u_{2} v_{2} \in E\left(G_{2}\right)\right]$. The vertex set of $G_{1}\left[G_{2}\right]$ is $V\left(G_{1}\right) \times V\left(G_{2}\right)$ and the degree of a vertex $(a, b)$ of $G_{1}\left[G_{2}\right]$ is given by $d_{G_{1}\left[G_{2}\right]}(a, b)=n_{2} d_{G_{1}}(a)+d_{G_{2}}(b)$. In the following theorem we compute the reformulated first Zagreb index of the composition of two graphs.

Theorem 4. The reformulated first Zagreb index of $G_{1}\left[G_{2}\right]$ is given by

$$
\begin{aligned}
E M_{1}\left(G_{1}\left[G_{2}\right]\right)= & \left|V\left(G_{1}\right)\right| E M_{1}\left(G_{2}\right)+\left|V\left(G_{2}\right)\right|^{4} E M_{1}\left(G_{1}\right)+4\left|V\left(G_{2}\right)\right|^{2}\left|E\left(G_{2}\right)\right| M_{1}\left(G_{1}\right) \\
& +2\left|V\left(G_{2}\right)\right|\left(M_{1}\left(G_{1}\right)-2\left|E\left(G_{1}\right)\right|\right)\left(4\left|V\left(G_{2}\right)\right|\left|E\left(G_{2}\right)\right|+2\left|V\left(G_{2}\right)\right|^{2}\left(\left|V\left(G_{2}\right)\right|-1\right)\right) \\
& +4\left|V\left(G_{2}\right)\right|^{2}\left|E\left(G_{1}\right)\right|\left(\left|V\left(G_{2}\right)\right|-1\right)^{2}+16\left|V\left(G_{2}\right)\right|\left|E\left(G_{1}\right)\right|\left|E\left(G_{2}\right)\right|\left(\left|V\left(G_{2}\right)\right|-2\right) \\
& +10\left|E\left(G_{1}\right)\right|\left|V\left(G_{2}\right)\right| M_{1}\left(G_{1}\right)+8\left|E\left(G_{1}\right)\right|\left|E\left(G_{2}\right)\right|^{2} .
\end{aligned}
$$

Proof of Theorem 4. We have

$$
\begin{aligned}
E M_{1}\left(G_{1}\left[G_{2}\right]\right)= & \sum_{(a, x)(b, y) \in E\left(G_{1}\left[G_{2}\right]\right)}\left(d_{G_{1}\left[G_{2}\right]}(a, x)+d_{G_{1}\left[G_{2}\right]}(b, y)-2\right)^{2} \\
= & \sum_{(a, x)(a, y) \in E\left(G_{1}\left[G_{2}\right]\right), x y \in E\left(G_{2}\right)}\left(d_{G_{1}\left[G_{2}\right]}(a, x)+d_{G_{1}\left[G_{2}\right]}(a, y)-2\right)^{2} \\
& +\sum_{(a, x)(b, y) \in E\left(G_{1}\left[G_{2}\right]\right), a b \in E\left(G_{1}\right)}\left(d_{G_{1}\left[G_{2}\right]}(a, x)+d_{G_{1}\left[G_{2}\right]}(b, y)-2\right)^{2} \\
= & C_{1}+C_{2} .
\end{aligned}
$$

where $C_{1}$ and $C_{2}$ denote the sums of the above terms in order. Next we calculate $C_{1}$ and $C_{2}$ separately.

Now,

$$
\begin{aligned}
C_{1}= & \sum_{(a, x)(a, y) \in E\left(G_{1}\left[G_{2}\right]\right), x y \in E\left(G_{2}\right)}\left(d_{G_{1}\left[G_{2}\right]}(a, x)+d_{G_{1}\left[G_{2}\right]}(a, y)-2\right)^{2} \\
= & \sum_{a \in V\left(G_{1}\right)} \sum_{x y \in E\left(G_{2}\right)}\left(2\left|V\left(G_{2}\right)\right| d_{G_{1}}(a)+d_{G_{2}}(x)+d_{G_{2}}(y)-2\right)^{2} \\
= & 4\left|V\left(G_{2}\right)\right|^{2} \sum_{x y \in E\left(G_{2}\right)} \sum_{a \in V\left(G_{1}\right)} d_{G_{1}}(a)^{2}+\sum_{a \in V\left(G_{1}\right)} \sum_{x y \in E\left(G_{2}\right)}\left(d_{G_{2}}(x)+d_{G_{2}}(y)-2\right)^{2} \\
& +4\left|V\left(G_{2}\right)\right| \sum_{a \in V\left(G_{1}\right)} d_{G_{1}}(a) \sum_{x y \in E\left(G_{2}\right)}\left(d_{G_{2}}(x)+d_{G_{2}}(y)-2\right)-8\left|V\left(G_{2}\right)\right| \sum_{x y \in E\left(G_{2}\right)} \sum_{a \in V\left(G_{1}\right)} d_{G_{1}}(a) \\
= & \left|V\left(G_{1}\right)\right| E M_{1}\left(G_{2}\right)+4\left|V\left(G_{2}\right)\right|^{2}\left|E\left(G_{2}\right)\right| M_{1}\left(G_{1}\right)+8\left|V\left(G_{2}\right)\right|\left|E\left(G_{1}\right)\right| M_{1}\left(G_{2}\right){ }^{2} \\
& -16\left|V\left(G_{2}\right)\right|\left|E\left(G_{1}\right)\right|\left|E\left(G_{2}\right)\right| .
\end{aligned}
$$


Also,

$$
\begin{aligned}
C_{2}= & \sum_{(a, x)(b, y) \in E\left(G_{1}\left[G_{2}\right]\right)}\left(d_{G_{1}\left[G_{2}\right]}(a, x)+d_{G_{1}\left[G_{2}\right]}(b, y)-2\right)^{2} \\
= & \sum_{x \in V\left(G_{2}\right)} \sum_{y \in V\left(G_{2}\right)} \sum_{a b \in E\left(G_{1}\right)}\left(\left|V\left(G_{2}\right)\right| d_{G_{1}}(a)+d_{G_{2}}(x)+\left|V\left(G_{2}\right)\right| d_{G_{1}}(b)+d_{G_{2}}(y)-2\right)^{2} \\
= & \sum_{x \in V\left(G_{2}\right)} \sum_{y \in V\left(G_{2}\right)} \sum_{a b \in E\left(G_{1}\right)}\left(\left|V\left(G_{2}\right)\right|\left(d_{G_{1}}(a)+d_{G_{1}}(b)-2\right)+d_{G_{2}}(x)+d_{G_{2}}(y)-2+2\left|V\left(G_{2}\right)\right|\right)^{2} \\
= & \left|V\left(G_{2}\right)\right|^{2} \sum_{x \in V\left(G_{2}\right)} \sum_{y \in V\left(G_{2}\right)} \sum_{a b \in E\left(G_{1}\right)}\left(d_{G_{1}}(a)+d_{G_{1}}(b)-2\right)^{2} \\
& +2\left|V\left(G_{2}\right)\right| \sum_{a b \in E\left(G_{1}\right)}\left(d_{G_{1}}(a)+d_{G_{1}}(b)-2\right) \sum_{x \in V\left(G_{2}\right)} \sum_{y \in V\left(G_{2}\right)}\left(d_{G_{2}}(x)+d_{G_{2}}(y)+2\left(\left|V\left(G_{2}\right)\right|-1\right)\right) \\
& +2\left|V\left(G_{2}\right)\right| \sum_{a b \in E\left(G_{1}\right)} \sum_{x \in V\left(G_{2}\right)} \sum_{y \in V\left(G_{2}\right)}\left(d_{G_{2}}(x)^{2}+d_{G_{2}}(y)^{2}+2 d_{G_{2}}(x) d_{G_{2}}(y)\right) \\
& +8\left|V\left(G_{2}\right)\right|\left(\left|V\left(G_{2}\right)\right|-1\right) \sum_{a b \in E\left(G_{1}\right)} \sum_{x \in V\left(G_{2}\right)} \sum_{y \in V\left(G_{2}\right)} 4\left(d_{G_{2}}(x)+d_{G_{2}}(y)\right) \\
= & 2\left|V\left(G_{2}\right)\right|\left(M_{1}\left(G_{1}\right)-2\left|E\left(G_{1}\right)\right|\right)\left(4\left|V\left(G_{2}\right)\right|\left|E\left(G_{2}\right)\right|+2\left|V\left(G_{2}\right)\right|^{2}\left(\left|V\left(G_{2}\right)\right|-1\right)\right) \\
& +4\left|V\left(G_{2}\right)\right|^{2}\left|E\left(G_{1}\right)\right|\left(\left|V\left(G_{2}\right)\right|-1\right)^{2}+2\left|V\left(G_{2}\right)\right|\left|E\left(G_{1}\right)\right| M_{1}\left(G_{2}\right)+8\left|E\left(G_{1}\right)\right|\left|E\left(G_{2}\right)\right|^{2} \\
& +\left|V\left(G_{2}\right)\right|^{4} E M_{1}\left(G_{1}\right)+16\left|V\left(G_{2}\right)\right|\left|E\left(G_{1}\right)\right|\left|E\left(G_{2}\right)\right|\left(\left|V\left(G_{2}\right)\right|-2\right) .
\end{aligned}
$$


Now combining $C_{1}$ and $C_{2}$, on simplification, the reformulated first Zagreb index of $G_{1}\left[G_{2}\right]$ is obtained as above.

Example 11. The fence graph and closed fence graph are defined as $P_{n}\left[P_{2}\right]$ and $C_{n}\left[P_{2}\right]$. So, from Theorem 4, the reformulated first Zagreb index of these graphs are given by

(i) $E M_{1}\left(P_{n}\left[P_{2}\right]\right)=320 n-576$

(ii) $E M_{1}\left(C_{n}\left[P_{2}\right]\right)=320 n$.

\subsection{Splice of Graphs}

A splice of $G_{1}$ and $G_{2}$ was introduced by Doslić [23]. Let $y \in V\left(G_{1}\right)$ and $z \in V\left(G_{2}\right)$ be two given vertices of $G_{1}$ and $G_{2}$ respectively. The splice of two graphs $G_{1}$ and $G_{2}$ at the vertices $y$ and $z$ is denoted by $\left(G_{1} \bullet G_{2}\right)(y, z)$ and is obtained by identifying the vertices $y$ and $z$ in the union of $G_{1}$ and $G_{2}$. The vertex set of $\left(G_{1} \bullet G_{2}\right)(y, z)$ is given by $V\left(\left(G_{1} \bullet G_{2}\right)(y, z)\right)=\left[V\left(G_{1}\right) \backslash\{y\}\right] \cup\left[V\left(G_{2}\right) \backslash\{z\}\right] \cup v_{12}$, where we denote the vertex obtained by identifying $y$ and $z$ by $v_{12}$. From the construction of the splice of two graphs it is clear that

$$
d_{G_{1} \bullet G_{2}(y, z)}(v)= \begin{cases}d_{G_{i}}(v), & \text { for } v \in V\left(G_{i}\right) \text { and } v \neq y, z \\ d_{G_{1}}(y)+d_{G_{2}}(z), & \text { for } v=v_{12}\end{cases}
$$

Let $N(v)$ denotes the set of vertices which are the neighbors of the vertex $v$, so that $|N(v)|=d_{G}(v)$. Also let

$$
\delta_{G}(v)=\sum_{u \in N(v)} d_{G}(u)
$$

i.e., sum of degrees of the neighbor vertices of $G$. In the following theorem we obtain the reformulated first Zagreb index of the splice of two graphs.

Theorem 5. The reformulated first Zagreb index of splice of graphs $G_{1}$ and $G_{2}$ is given by

$$
\begin{aligned}
E M_{1}\left(\left(G_{1} \bullet G_{2}\right)(y, z)\right)= & E M_{1}\left(G_{1}\right)+E M_{1}\left(G_{2}\right)+3 d_{G_{1}}(y)^{2} d_{G_{2}}(z)+3 d_{G_{1}}(y) d_{G_{2}}(z)^{2} \\
& +2 d_{G_{1}}(y) \delta_{G_{2}}(z)+2 d_{G_{2}}(z) \delta_{G_{1}}(y)-d_{G_{1}}(y)-d_{G_{2}}(z) .
\end{aligned}
$$


Proof of Theorem 5. We have, from the definition of the reformulated first Zagreb index

$$
\begin{aligned}
& E M_{1}\left(\left(G_{1} \bullet G_{2}\right)(y, z)\right)=\sum_{(u, v) \in E\left(\left(G_{1} \bullet G_{2}\right)(y, z)\right)}\left(d_{\left(G_{1} \bullet G_{2}\right)(y, z)}(u)+d_{\left(G_{1} \bullet G_{2}\right)(y, z)}(v)-2\right)^{2} \\
& =\sum_{(u, v) \in E\left(G_{1}\right) u v \neq y}\left(d_{G_{1}}(u)+d_{G_{1}}(v)-2\right)^{2} \\
& +\sum_{(u, v) \in E\left(G_{2}\right) u v \neq z}\left(d_{G_{2}}(u)+d_{G_{2}}(v)-2\right)^{2} \\
& +\sum_{(u, v) \in E\left(G_{1}\right), u=y, v \in V\left(G_{1}\right)}\left(d_{G_{1}}(y)+d_{G_{2}}(z)+d_{G_{1}}(v)-2\right)^{2} \\
& +\sum_{(u, v) \in E\left(G_{2}\right) u=z, v \in V\left(G_{2}\right)}\left(d_{G_{1}}(y)+d_{G_{2}}(z)+d_{G_{2}}(v)-2\right)^{2} \\
& =\sum_{(u, v) \in E\left(G_{1}\right) u v \neq y}\left(d_{G_{1}}(u)+d_{G_{1}}(v)-2\right)^{2} \\
& +\sum_{(u, v) \in E\left(G_{2}\right) u v \neq z}\left(d_{G_{2}}(u)+d_{G_{2}}(v)-2\right)^{2} \\
& +\sum_{(u, v) \in E\left(G_{1}\right), u=y, v \in V\left(G_{1}\right)}\left(d_{G_{1}}(y)+d_{G_{1}}(v)-2\right)^{2} \\
& +\sum_{(u, v) \in E\left(G_{2}\right) u=z, v \in V\left(G_{2}\right)}\left(d_{G_{2}}(z)+d_{G_{2}}(v)-2\right)^{2} \\
& +\sum_{(u, v) \in E\left(G_{1}\right), u=y, v \in V\left(G_{1}\right)} d_{G_{2}}(z)^{2}+\sum_{(u, v) \in E\left(G_{2}\right) u=z, v \in V\left(G_{2}\right)} d_{G_{1}}(y)^{2} \\
& +\sum_{(u, v) \in E\left(G_{1}\right), u=y, v \in V\left(G_{1}\right)} 2 d_{G_{2}}(z)\left(d_{G_{1}}(y)+d_{G_{1}}(v)-2\right) \\
& +\sum_{(u, v) \in E\left(G_{2}\right) u=z, v \in V\left(G_{2}\right)} 2 d_{G_{1}}(y)\left(d_{G_{2}}(z)+d_{G_{2}}(v)-2\right) \\
& =E M_{1}\left(G_{1}\right)+E M_{1}\left(G_{2}\right)+d_{G_{1}}(y)^{2} d_{G_{2}}(z)+d_{G_{1}}(y) d_{G_{2}}(z)^{2} \\
& +2 d_{G_{2}}(z)\left(d_{G_{1}}(y)^{2}+\delta_{G_{1}}(y)-2 d_{G_{1}}(y)\right) \\
& +2 d_{G_{1}}(y)\left(d_{G_{2}}(z)^{2}+\delta_{G_{2}}(z)-2 d_{G_{2}}(z)\right) \text {. }
\end{aligned}
$$

From the above, after simple computation, the desired result follows.

\subsection{Link of Graphs}

A link of $G_{1}$ and $G_{2}$ at the vertices $y$ and $z$ is denoted by $\left(G_{1} \sim G_{2}\right)(y, z)$ and is obtained by joining the vertices $y$ and $z$ in the union of $G_{1}$ and $G_{2}$. From the construction of link graphs, it is clear that

$$
d_{\left(G_{1} \sim G_{2}\right)_{(y, z)}}(v)= \begin{cases}d_{G_{i}}(v), & v \in V\left(G_{i}\right), i=1,2, \text { and } v \neq y, z, \\ d_{G_{i}}(v)+1, & v=y, z\end{cases}
$$

In the following theorem we obtain the reformulated first Zagreb index of the link of two graphs. 
Theorem 6. The reformulated first Zagreb index of link of graphs $G_{1}$ and $G_{2}$ is given by

$$
\begin{aligned}
E M_{1}\left(\left(G_{1} \sim G_{2}\right)(y, z)\right)= & E M_{1}\left(G_{1}\right)+E M_{1}\left(G_{2}\right)+3 d_{G_{1}}(y)^{2}+3 d_{G_{2}}(z)^{2}+2 d_{G_{1}}(y) d_{G_{2}}(z) \\
& +2 \delta_{G_{1}}(y)+3 \delta_{G_{2}}(z)-3 d_{G_{1}}(y)-3 d_{G_{2}}(z)
\end{aligned}
$$

Proof of Theorem 6. From the definition of the reformulated first Zagreb index, we have

$$
\begin{aligned}
& E M_{1}\left(\left(G_{1} \sim G_{2}\right)(y, z)\right)=\sum_{(u, v) \in E\left(\left(G_{1} \sim G_{2}\right)(y, z)\right)}\left(d_{\left(G_{1} \sim G_{2}\right)(y, z)}(u)+d_{\left(G_{1} \sim G_{2}\right)(y, z)}(v)-2\right)^{2} \\
& =\sum_{(u, v) \in E\left(G_{1}\right) u v \neq y}\left(d_{G_{1}}(u)+d_{G_{1}}(v)-2\right)^{2} \\
& +\sum_{(u, v) \in E\left(G_{2}\right) u v \neq z}\left(d_{G_{2}}(u)+d_{G_{2}}(v)-2\right)^{2} \\
& +\sum_{(u, v) \in E\left(G_{1}\right), u=y, v \in V\left(G_{1}\right)}\left(1+d_{G_{1}}(y)+d_{G_{1}}(v)-2\right)^{2} \\
& =\sum_{(u, v) \in E\left(G_{1}\right) u v \neq y}\left(d_{G_{1}}(u)+d_{G_{1}}(v)-2\right)^{2} \\
& +\sum_{(u, v) \in E\left(G_{2}\right) u v \neq z}\left(d_{G_{2}}(u)+d_{G_{2}}(v)-2\right)^{2} \\
& +\sum_{(u, v) \in E\left(G_{1}\right), u=y, v \in V\left(G_{1}\right)}\left(1+d_{G_{1}}(y)+d_{G_{1}}(v)-2\right)^{2} \\
& +\sum_{(u, v) \in E\left(G_{2}\right) u=z, v \in V\left(G_{2}\right)}\left(1+d_{G_{2}}(z)+d_{G_{2}}(v)-2\right)^{2} \\
& +\left\{\left(d_{G_{1}}(y)+1\right)+\left(d_{G_{2}}(z)+1\right)-2\right\}^{2} \\
& =\sum_{(u, v) \in E\left(G_{1}\right)}\left(d_{G_{1}}(u)+d_{G_{1}}(v)-2\right)^{2} \\
& +\sum_{(u, v) \in E\left(G_{2}\right)}\left(d_{G_{2}}(u)+d_{G_{2}}(v)-2\right)^{2} \\
& +2 \sum_{(u, v) \in E\left(G_{1}\right), u=y, v \in V\left(G_{1}\right)}\left(d_{G_{1}}(u)+d_{G_{1}}(v)-2\right)^{2} \\
& +2 \sum_{(u, v) \in E\left(G_{2}\right), u=z, v \in V\left(G_{2}\right)}\left(d_{G_{2}}(u)+d_{G_{2}}(v)-2\right)^{2} \\
& +2 \sum_{(u, v) \in E\left(G_{1}\right), u=y, v \in V\left(G_{1}\right)} 1+\sum_{(u, v) \in E\left(G_{2}\right), u=z, v \in V\left(G_{2}\right)} 1 \\
& +\left(d_{G_{2}}(y)+d_{G_{2}}(z)\right)^{2} \\
& =E M_{1}\left(G_{1}\right)+E M_{1}\left(G_{2}\right)+2 d_{G_{1}}(y)^{2}+2 \delta_{G_{1}}(y)-4 d_{G_{1}}(y)+2 d_{G_{2}}(z)^{2} \\
& +2 \delta_{G_{2}}(z)-4 d_{G_{2}}(z)+d_{G_{1}}(y)+d_{G_{2}}(z)+\left(d_{G_{1}}(y)+d_{G_{2}}(z)\right)^{2}
\end{aligned}
$$

From the above, we get the desired result after simple computation. 


\subsection{Corona Product of Graphs}

The corona product $G_{1} \odot G_{2}$ of two graphs is obtained by taking one copy of $G_{1}$ and $n_{1}$ copies of $G_{2}$; and by joining each vertex of the $i$-th copy of $G_{2}$ to the $i$-th vertex of $G_{1}$, where $1 \leq i \leq\left|V\left(G_{1}\right)\right|$. The corona product of $G_{1}$ and $G_{2}$ has a total of $\left(\left|V\left(G_{1}\right)\right|\left|V\left(G_{2}\right)\right|+\left|V\left(G_{1}\right)\right|\right)$ vertices and $\left(\left|E\left(G_{1}\right)\right|+\right.$ $\left.\left|V\left(G_{1}\right)\right|\left|E\left(G_{2}\right)\right|+\left|V\left(G_{1}\right)\right|\left|V\left(G_{2}\right)\right|\right)$ edges. Clearly, the corona product operation of two graphs is not commutative. Different topological indices of the corona product of two graphs have already been studied in [24,25]. Let the vertices of $G_{1}$ be denoted by $V\left(G_{1}\right)=\left\{u_{1}, u_{2}, \ldots, u_{\left|V\left(G_{1}\right)\right|}\right\}$ and the vertices of the i-th copy of $G_{2}$ are denoted by $V\left(G_{2}^{i}\right)=\left\{v_{1}^{i}, v_{2}^{i}, \ldots, v_{n_{2}}^{i}\right\}$ for $i=1,2, \ldots,\left|V\left(G_{1}\right)\right|$. Thus the vertex and edge sets of $G_{1} \odot G_{2}$ are given by $V\left(G_{1} \odot G_{2}\right)=V\left(G_{1}\right) \quad \bigcup \quad V\left(G_{2, i}\right)$ and $E\left(G_{1} \odot G_{2}\right)=E\left(G_{1}\right) \bigcup_{i=1,2, \ldots,\left|V\left(G_{1}\right)\right|} E\left(G_{2, i}\right) \bigcup\left\{u_{i}, v_{j}: u_{i} \in V\left(G_{1}\right), v_{j}^{i} \in V\left(G_{2, i}\right)\right\}$. By definition, the degree of a vertex $v$ of $G_{1} \odot G_{2}$ is given by

$$
d_{G_{1} \odot G_{2}}(v)=\left\{\begin{array}{l}
d_{G_{1}}(v)+n_{2}, v \in V\left(G_{1}\right) \\
d_{G_{2, i}}(v)+1, v \in V\left(G_{2, i}\right), i=1,2, \ldots\left|V\left(G_{1}\right)\right|
\end{array}\right.
$$

In the following, we compute the reformulated first Zagreb index of the corona product of two graphs.

Theorem 7. The reformulated first Zagreb index of $G_{1} \odot G_{2}$ is given by

$$
\begin{aligned}
E M_{1}\left(G_{1} \odot G_{2}\right)= & E M_{1}\left(G_{1}\right)+\left|V\left(G_{1}\right)\right| E M_{1}\left(G_{2}\right)+5\left|V\left(G_{2}\right)\right| M_{1}\left(G_{1}\right)+5\left|V\left(G_{1}\right)\right| M_{1}\left(G_{2}\right) \\
& +4\left|V\left(G_{1}\right)\right|\left|E\left(G_{2}\right)\right|\left(\left|V\left(G_{2}\right)\right|-2\right)+4\left|V\left(G_{2}\right)\right|\left|E\left(G_{1}\right)\right|\left(2\left|V\left(G_{2}\right)\right|-3\right) \\
& +4\left|V\left(G_{1}\right)\right|\left|V\left(G_{2}\right)\right|\left(\left|V\left(G_{2}\right)\right|-1\right)^{2}+8\left|E\left(G_{1}\right)\right|\left|E\left(G_{2}\right)\right| .
\end{aligned}
$$

Proof of Theorem 7. Let $\left|V\left(G_{i}\right)\right|=n_{i}\left|E\left(G_{i}\right)\right|=e_{i}$, for $i \in\{1,2\}$, then the edge set of $G_{1} \odot G_{2}$ can be partitioned into three subsets

$$
\begin{aligned}
& E_{1}=\left\{u v \in E\left(G_{1} \odot G_{2}\right): u, v \in V\left(G_{1}\right), i=1,2, \ldots, n_{1}\right\}, \\
& E_{2}=\left\{u v \in E\left(G_{1} \odot G_{2}\right): u \in V\left(G_{1}\right), v \in V\left(G_{2, i}\right), i=1,2, \ldots, n_{1}\right\}, \text { and } \\
& E_{3}=\left\{u v \in E\left(G_{1} \odot G_{2}\right): u \in V\left(G_{1}\right), v \in V\left(G_{2, i}\right), i=1,2, \ldots, n_{1}\right\} .
\end{aligned}
$$

To calculate the reformulated first Zagreb index of $G_{1} \odot G_{2}$, we consider the following cases.

CASE 1. If $e \in E_{1}$ then $d_{G_{1} \odot G_{2}}(e)=d_{G_{1} \odot G_{2}}\left(u_{i}\right)+d_{G_{1} \odot G_{2}}\left(v_{i}\right)-2=d_{G_{1}}\left(u_{i}\right)+d_{G_{1}}\left(v_{i}\right)+2\left(n_{2}-1\right)$, for $i=1,2, \ldots, n_{1}$. So the contribution of these type of edges to the reformulated first Zagreb index of $G_{1} \odot G_{2}$ is

$$
\begin{aligned}
Q_{1} & =\sum_{e \in E_{1}} d_{G_{1} \odot G_{2}}(e)^{2} \\
& =\sum_{u_{i} v_{i} \in E\left(G_{1}\right)}\left(d_{G_{1}}\left(u_{i}\right)+d_{G_{1}}\left(v_{i}\right)+2\left(n_{2}-1\right)\right)^{2} \\
& =\sum_{u_{i} v_{i} \in E\left(G_{1}\right)}\left\{\left(d_{G_{1}}\left(u_{i}\right)+d_{G_{1}}\left(v_{i}\right)-2\right)^{2}+4 n_{2}{ }^{2}+4 n_{2}\left(d_{G_{1}}\left(u_{i}\right)+d_{G_{1}}\left(v_{i}\right)-2\right)\right\} \\
& =E M_{1}\left(G_{1}\right)+4 n_{2}{ }^{2} m_{1}+4 n_{2} M_{1}\left(G_{1}\right)-8 n_{2} m_{1} .
\end{aligned}
$$


CASE 2. Let $e \in E_{2}$, then $d_{G_{1} \odot G_{2}}(e)=d_{G_{1} \odot G_{2}}\left(u_{j}\right)+d_{G_{1} \odot G_{2}}\left(v_{j}\right)-2=d_{G_{1}}\left(u_{i}\right)+d_{G_{2}}\left(v_{j}\right)$, for $j=1,2, \ldots, n_{2}$. So, the contribution of these type of edges to the reformulated first Zagreb index of $G_{1} \odot G_{2}$ is given by

$$
\begin{aligned}
Q_{2} & =\sum_{i=1}^{n_{1}} \sum_{u_{j} v_{j} \in E\left(G_{2}\right)}\left(d_{G_{2}}\left(u_{j}\right)+d_{G_{2}}\left(v_{j}\right)\right)^{2} \\
& =\sum_{i=1}^{n_{1}} \sum_{u_{j} v_{j} \in E\left(G_{2}\right)}\left\{\left(d_{G_{2}}\left(u_{j}\right)+d_{G_{2}}\left(v_{j}\right)-2\right)^{2}+4\left(d_{G_{2}}\left(u_{j}\right)+d_{G_{2}}\left(v_{j}\right)-2\right)+4\right\} \\
& =\sum_{i=1}^{n_{1}}\left(E M_{1}\left(G_{2}\right)+4 M_{1}\left(G_{2}\right)-8 m_{2}+4 m_{2}\right) \\
& =n_{1} E M_{1}\left(G_{2}\right)+4 n_{1} M_{1}\left(G_{2}\right)-4 n_{1} m_{2} .
\end{aligned}
$$

CASE 3. Let $e \in E_{3}$, then $d_{G_{1} \odot G_{2}}(e)=d_{G_{1} \odot G_{2}}\left(u_{i}\right)+d_{G_{1} \odot G_{2}}\left(v_{j}\right)-2=d_{G_{1}}\left(u_{i}\right)+n_{2}+d_{G_{2}}\left(v_{j}\right)+1-2$ $=d_{G_{1}}\left(u_{i}\right)+d_{G_{2}}\left(v_{j}\right)+n_{2}-1$, for $i=1,2, \ldots, n_{1}$ and $j=1,2, \ldots, n_{2}$. So the contribution of these type of edges to the reformulated first Zagreb index of $G_{1} \odot G_{2}$ is given by

$$
\begin{aligned}
Q_{3}= & \sum_{i=1}^{n_{1}} \sum_{j=1}^{n_{2}}\left(d_{G_{1}}\left(u_{i}\right)+d_{G_{2}}\left(v_{j}\right)+n_{2}-1\right)^{2} \\
= & \sum_{i=1}^{n_{1}} \sum_{j=1}^{n_{2}}\left\{d_{G_{1}}\left(u_{i}\right)^{2}+d_{G_{2}}\left(v_{j}\right)^{2}+2\left(n_{2}-1\right)^{2}+2\left(n_{2}-1\right) d_{G_{1}}\left(u_{i}\right)+2\left(n_{2}-1\right) d_{G_{2}}\left(v_{j}\right)\right\} \\
& +2 \sum_{i=1}^{n_{1}} \sum_{j=1}^{n_{2}} d_{G_{1}}\left(u_{i}\right) d_{G_{2}}\left(u_{j}\right) \\
= & n_{2} M_{1}\left(G_{1}\right)+n_{1} M_{1}\left(G_{2}\right)+4 n_{1} n_{2}\left(n_{2}-1\right)^{2}+4 n_{2} m_{1}\left(n_{2}-1\right)+4 n_{1} m_{2}\left(n_{2}-1\right)+8 m_{1} m_{2} .
\end{aligned}
$$

The reformulated Zagreb first index of $G_{1} \odot G_{2}$ is obtained by adding $Q_{1}, Q_{2}$ and $Q_{3}$ then simplifying the expression.

Corollary 8. The bottleneck graph of a graph $G$ is defined as the corona product of $K_{2}$ and $G$. Thus, its reformulated first Zagreb index is given by

$$
E M_{1}\left(K_{2} \odot G\right)=E M_{1}(G)+10 M_{1}(G)+2 n^{2}(n+2)+8 m(n-1) .
$$

A $t$-thorny graph is obtained by joining $t$ thorns to each vertex of any given graph $G$. An edge $e=(u, v)$ of a graph $G$ is called a thorn if either $d(u)=1$ or $d(v)=1$. A variety of topological indices of thorn graphs have been already studied by the researchers [26-29]. The $t$-thorny graph of $G$ is obtained from corona product of $G$ and the complement of the complete graph $K_{t}$. So, from Theorem 7 , the following corollary follows.

Corollary 9. The reformulated first Zagreb index of the t-thorny graph is given by

$$
E M_{1}\left(G^{t}\right)=E M_{1}(G)+5 t M_{1}(G)+4 m t(2 t-3)+n t(t-1)^{2} .
$$

Example 12. The reformulated first Zagreb index of t-thorny path $\left(P_{n}{ }^{t}\right)$ and t-thorny cycle $\left(C_{n}{ }^{t}\right)$ are calculated as

(i) $E M_{1}\left(P_{n}{ }^{t}\right)=n t^{3}+6 n t^{2}+9 n t-8 t^{2}-18 t+4 n-10$

(ii) $E M_{1}\left(C_{n}{ }^{t}\right)=n t^{3}+6 n t^{2}+9 n t+4 n$. 
Next, we calculate the reformulated first Zagreb index of some particular bridge graphs. Let $G_{1}, G_{2}, \ldots, G_{n}$ be a set of finite pairwise disjoint graphs. The bridge graph with respect to the vertices $v_{1}, v_{2}, \ldots, v_{n}$, denoted by $B\left(G_{1}, G_{2}, \ldots, G_{n} ; v_{1}, v_{2}, \ldots, v_{n}\right)$ is the graph obtained by connecting the vertices $v_{i}$ and $v_{i+1}$ of $G_{i}$ and $G_{i+1}$ by an edge for all $i=1,2, \ldots,(n-1)$. If $G_{1} \cong G_{2} \cong \ldots \cong G_{n}$ and $v_{1}=v_{2}=\ldots=v_{n}=v$, we define $G_{n}(G, v)=B(G, G, \ldots, G ; v, v, \ldots, v)$. In particular, $B_{n}=G_{n}\left(P_{3}, v\right)$ and $T_{n, k}=G_{n}\left(C_{k}, u\right)$ are two special types of bridge graphs. Then, from the definition of the corona product of graphs, $B_{n} \cong P_{n} \odot \bar{K}_{2}$ and $T_{n, 3} \cong P_{n} \odot K_{2}$. Using Theorem 7, the reformulated first Zagreb index of these bridge graphs are obtained as follows.

Example 13. (i) $E M_{1}\left(B_{n}\right)=5 n-78$, for $n \geq 3$.

(ii) $E M_{1}\left(T_{m, 3}\right)=72 m-86$, for $m \geq 3$.

(iii) $E M_{1}\left(J_{n, m+1}\right)=n m\left(m^{2}+10 m+33\right)-2 m(4 m+13)+4 n-10$, for $n \geq 3$ and $m \geq 3$.

\section{Conclusions}

In this paper, we have studied the reformulated first Zagreb index of different graph operations. Also, we applied our results to calculate the reformulated first Zagreb index of some classes of graphs by specializing the components of graph operations. Nevertheless, there are still many other graph operations and special classes of graphs that are not covered here. For further research, the second reformulated Zagreb index various graph operations can be computed.

\section{Acknowledgments}

The authors would like to thank the two referees for their constructive remarks which have greatly improved the manuscript.

\section{Author Contributions}

All three authors have significant contribution to this paper and the final form of this paper is approved by all three authors.

\section{Conflicts of Interest}

The authors declare no conflict of interest.

\section{References}

1. Gutman, I.; Trinajstić, N. Graph theory and molecular orbitals total $\pi$-electron energy of alternant hydrocarbons. Chem. Phys. Lett. 1972, 17, 535-538.

2. Xu, K.; Tang, K.; Liu, H.; Wang, J. The Zagreb indices of bipartite graphs with more edges. J. Appl. Math. Inf. 2015 33, 365-377.

3. Das, K.C.; Xu, K.; Nam, J. On Zagreb indices of graphs. Front. Math. China 2015, 10, 567-582.

4. Milićević, A.; Nikolić, S.; Trinajstić, N. On reformulated Zagreb indices. Mol. Divers. 2004, 8, 393-399. 
5. Zhou, B.; Trinajstić, N. Some properties of the reformulated Zagreb indices. J. Math. Chem. 2010, $48,714-719$.

6. Ilić, A.; Zhou, B. On reformulated Zagreb indices. Discret. Appl. Math. 2012, 160, 204-209.

7. Su, G.; Xiong, L.; Xu, L.; Ma, B. On the maximum and minimum first reformulated Zagreb index with connectivity at most k. Filomat 2011, 2, 75-83.

8. De, N. Some Bounds of Reformulated Zagreb Indices. Appl. Math. Sci. 2012, 6, 5005-5012.

9. De, N. Reformulated Zagreb indices of Dendrimers. Math. Aeterna 2013, 3, 133-138.

10. Ji, S.; Li, X.; Huo, B. On Reformulated Zagreb Indices with Respect to Acyclic, Unicyclic and Bicyclic Graphs. MATCH Commun. Math. Comput. Chem. 2014, 72, 723-732.

11. Ji, S.; Li, X.; Qu, Y. On reformulated zagreb indices with respect to tricyclic graphs. http://arxiv.org/abs/1406.7169.

12. Khalifeha, M.H.; Yousefi-Azaria, H.; Ashrafi, A.R. The first and second Zagreb indices of some graph operations. Discret. Appl. Math. 2009, 157, 804-811.

13. Ashrafi, A.R.; Doslić, T.; Hamzeh, A. The Zagreb coindices of graph operations. Discret. Appl. Math. 2010, 158, 1571-1578.

14. Das, K.C.; Yurttas, A.; Togan, M.; Cevik, A.S.; Cangul, I.N. The multiplicative Zagreb indices of graph operations. J. Ineql. Appl. 2013, 2013, doi:10.1186/1029-242X-2013-90.

15. Azari, M.; Iranmanesh, A. Computing the eccentric-distance sum for graph operations. Discret. Appl. Math. 2013, 161, 2827-2840.

16. De, N.; Pal, A.; Nayeem, S.M.A. On some bounds and exact formulae for connective eccentric indices of graphs under some graph operations. Int. J. Comb. 2014, doi:10.1155/2014/579257.

17. De, N.; Nayeem, S.M.A.; Pal, A. F-index of some graph operations. Personal communication, 2015.

18. Azari, M. Sharp lower bounds on the Narumi-Katayama index of graph operations. Appl. Math. Comput. 2014, 239, 409-421.

19. Khalifeh, M.H.; Yousefi-Azari, H.; Ashrafi, A.R. The hyper-Wiener index of graph operations. Comput. Math. Appl. 2008, 56, 1402-1407.

20. Tavakoli, M.; Rahbarnia, F.; Ashrafi, A.R. Some new results on irregularity of graphs. J. Appl. Math. Inf. 2014, 32, 675-685.

21. Veylaki, M.; Nikmehr, M.J.; Tavallaee, H.A. The third and hyper-Zagreb coindices of some graph operations. J. Appl. Math. Comput. 2015, doi:10.1007/s12190-015-0872-z.

22. De, N.; Nayeem, S.M.A.; Pal, A. Total eccentricity index of the generalized hierarchical product of graphs. Int. J. Appl. Comput. Math. 2014, doi:10.1007/s40819-014-0016-4.

23. Doslić, T. Splices, links and their degree weighted Wiener polynomials. Graph Theory Notes N. Y. 2005, 48, 47-55.

24. Pattabiraman, K.; Kandan, P. Weighted PI index of corona product of graphs. Discret. Math. Algorithms Appl. 2014, 6, doi:10.1142/S1793830914500554.

25. Yarahmadi, Z.; Ashrafi, A.R. The Szeged, Vertex PI, first and second Zagreb Indices of corona Product of Graphs. Filomat 2012, 26, 467-472.

26. Alizadeh, Y.; Iranmanesh, A.; Doslić, T.; Azari, M. The edge Wiener index of suspensions, bottlenecks, and thorny graphs. Glas. Mat. Ser. III 2014, 49, 1-12. 
27. De, N. On eccentric connectivity index and polynomial of thorn graph. Appl. Math. 2012, 3, 931-934.

28. De, N. Augmented eccentric connectivity index of some thorn graphs. Int. J. Appl. Math. Res. 2012, 1, 671-680.

29. De, N.; Pal, A.; Nayeem, S.M.A. Modified eccentric connectivity of generalized thorn graphs. Int. J. Comput. Math. 2014, doi:10.1155/2014/436140.

(C) 2015 by the authors; licensee MDPI, Basel, Switzerland. This article is an open access article distributed under the terms and conditions of the Creative Commons Attribution license (http://creativecommons.org/licenses/by/4.0/). 